\title{
ASTRONOMY AS A LIBERAL ART
}

\author{
Tom R. Dennis
}

Mount Holyoke College, Five College Astronomy Department, South Hadley, Massachusetts 01075, U.S.A.

Every year in the United States, many thousands of university and college students take a one-semester course in astronomy as part of a "Liberal Arts" curriculum. At many institutions these courses are the raison d'etre for the astronomy program, and at most other institutions they are viewed as an important term in calculating an astronomy department's contribution.

I have often had a sense that what we are doing in these courses ${ }^{1}$ is counterproductive to any serious understanding of the goals of liberal arts curriculum. Over the last six or seven years, as I have been participating in my college's efforts ${ }^{2}$ to introduce a year-long, interdisciplinary survey of the humanities into our curriculum, this hunch has been confirmed: in our efforts to fit astronomy into the liberal-arts curriculum, we have ironically been undermining the enterprise.

The problem originates when teachers (and textbook authors) quite accurately perceive that the students in these courses are not scientists: few of them have taken science during the last two years of high school, and have certainly not taken chemistry and physics; and while most have taken (and passed) 11 or 12 years of math, they appear to have learned almost nothing, and are often hostile to the subject. Most of them consider themselves "weak in science [and/or] math."

As a response to these deficits, we decide to teach a "descriptive" course in astronomy. And at that moment, we inevitably commit ourselves not only to reinforcing their negative self-evaluation but also to misrepresenting the character of science.

Negative Self-evaluation: By presenting these students with a mass of "facts" about the universe, we essentially assign them a substitute task, which they can pursue instead of taking a "real" science course.

This works - insofar as it works - because most students who are sufficiently disciplined to have reached college can ingest a few "facts" and regurgitate them at the appropriate time.

But they still "do not understand." Indeed, one suspects that the mass of "facts" they "do not understand" has only increased, and so their impression of being intellectually inferior is unmodified at best, or perhaps proportionately increased. Certainly, by the very act of making a special course available, the instructor and the institution are reinforcing the judgment that some students cannot be expected to do "real science." 3 Many of them feel consigned to live in a universe that defies

\footnotetext{
${ }^{1}$ And I have taught such a course at least 33 times.

${ }^{2}$ Funded by a grant from the Mellon Foundation.

${ }^{3}$ In my institution students call these "baby" courses - "baby astro." There are no "baby"
} 
comprehension, but which certain untrustworthy wizards (scientists and engineers) seem to be able to manipulate almost at will. But at least the science requirement is out of the way.

Misrepresenting Science: Consider an anthropologist's view of a professor lecturing to a descriptive "Astro 101" class. There is an authority figure describing almost unbelievable things: holes in space-time, or ionization at the edge of infinity. ${ }^{4}$ The homily is reinforced by catechism: students learn responses to questions, and their perseverance and skill are taken as a measure of their good works.

What is wrong here is that the uniqueness of science is missing: by ignoring the revolutionary, anti-authoritarian epistemology of science, we present something indistinguishable from magic, superstition, political ideology, or theology. As Neil Harris, a historian at the University of Chicago, ${ }^{5}$ has put it, "Contemporary science is believed in by a credulous public rather than understood by an informed one."

This mind-set leaves the public open to all sorts of pseudosciences, from creationism to astrology. And the evidence is that the pseudosciences are winning: according to Martin Gardner ${ }^{6}$

A 1984 Gallup poll showed that the number of teen-agers who say they believe in astrology had risen from 40 percent in 1971 to 55 percent. Among teens who claim to believe in astrology, those from well-educated families outnumber those from untutored classes, and whites outnumber blacks.

Even in the community of intellectuals - professors of the humanities and social sciences - there are individuals who fail to understand the epistemological differences between physical science and their own disciplines, and consequently foist a $20^{t h}$-century version of scholasticism upon Harris' "credulous public."

An effort at reform: For the last several semesters I have been addressing these issues in my teaching, using my own text materials. The hallmarks of my approach include:

- A Conceptual Outline, which begins with a discussion of the spatial and temporal structure of the universe, and builds to a treatment of cosmic evolution informed by extensive use of the principle of conservation of energy;

- Quantitative, but Elementary Treatment, utilizing elementary algebra and "scientific notation," but no magnitudes, logarithms, or trigonometry;

- Regular Problem Assignments, emphasizing problems that illustrate and reinforce the argument of the book, rather than problem-solving ability per se;

courses in the humanities.

${ }^{4}$ To borrow a phrase from a literary friend, in a conversation about the origin of the cosmic microwave background.

${ }^{5}$ In a review of How Superstition Won and Science Lost, by John C. Burnham, in Science 240, 1552, 1988. Harris continues: "Today's popularizing processes, compared with some earlier versions, seem condescendingly simple-minded or narrowly opportunistic."

${ }^{6}$ New York Review of Books, 1988 June 10. 
- Laboratory Work, including naked-eye and telescopic observations (for which they must set the telescope themselves, using coordinates and sidereal clock);

- Explicit Connections with the Humanities, in an effort to develop an appreciation of science that goes beneath the "gee whiz" level.

This is still in an early stage of development, but I am truly encouraged with how well the experiment is working out. Perhaps the most encouraging aspect of it is that students do not really consider it nearly as different as I do - they are accustomed to taking math courses, and this therefore looks very familiar to them. I therefore suspect that as a community we have simply overreacted to the declining quality of mathematics instruction in the schools; rather than opting to eliminate the quantitative content from our courses, we can instead adapt our teaching materials and syllabus to provide the increased support these students require.

\section{COMPARATIVE METHODS FOR TEACHING AN ASTRONOMICAL TOPIC}

\section{Syuzo Isobe}

National Astronomical Observatory, Osawa, Mitaka, Tokyo 181, Japan

Astronomy has greatly progressed in this decade. The number of people who are interested in astronomical phenomena is certainly increasing as the number of IAU members increases. These people are divided into several categories, depending on their degrees of interests. For Japan, these are as follows:

\begin{tabular}{ccl} 
Categories & $\begin{array}{c}\text { Rough Number } \\
\text { of People }\end{array}$ & \multicolumn{1}{c}{ Definition } \\
A & $10^{2}$ & produce useful observational data \\
B & $10^{3}$ & observe frequently \\
C & $10^{4}$ & observe several times per year \\
D & $10^{5}$ & read astronomical magazines \\
E & $10^{6}$ & read general science magazines \\
F & $10^{7}$ & read scientific articles in newspapers \\
G & $10^{8}$ & no interest in science
\end{tabular}

The situation is changed when some such special event, such as a return of Halley's comet, occurs. We can say that our present target in teaching astronomy is to increase the number of people in each category except the last one. 